\title{
Investigating surface production reactions indoors using a detailed chemical model
}

\author{
M. Kruza ${ }^{1}$, N. Carslaw ${ }^{1} \&$ A. Lewis ${ }^{2}$ \\ ${ }^{1}$ Environment Department, University of York, UK \\ ${ }^{2}$ Department of Chemistry, University of York, UK
}

\begin{abstract}
Increasing attention is being paid to indoor air quality and building related symptoms such as headaches, allergy and eye irritation. Indoor air pollutants are generated through activities such as cooking, cleaning or smoking, as well as emitted from building materials, paints, carpets, furnishing and cleaning products. They can also ingress from outdoors, and consequently, indoor environments often contain higher concentrations of air pollutants than outdoors. There is increasing evidence that secondary air pollutants may be responsible for some of the observed health effects indoors. Such secondary pollutants can be a by-product of surface production reactions indoors. An indoor chemical model (INDCM) that employs a detailed chemical mechanism has been used to investigate surface interactions indoors. Through modelling surface emissions, it is possible to investigate how they impact on the indoor air quality. The study shows that air pollutants can be removed from indoor air on a variety of surfaces commonly found in the indoor environment. Further, these reactions lead to the production of a range of species such as aldehydes, which may be of concern for health.
\end{abstract}

Keywords: indoor air quality, VOC, secondary indoor air pollutants, modelling indoor air pollution, surface production.

\section{Introduction}

Over recent decades, much attention has been paid to outdoor air pollution but relatively little to the indoor environment. This is despite the fact that people spend approximately $90 \%$ of their time indoors (Carslaw [1]). Since the 1970s, 
indoor air quality has been of increasing concern. Indoor air pollution is associated with building related symptoms such as headaches, allergy, skin and eye irritation (often labeled as 'sick building syndrome'), but also carcinogenic and mutagenic effects (Jurvelin et al. [2]). Indeed, recent research shows that indoor air pollution can be more dangerous for human health than that present outdoors (Salthammer et al. [3]).

Indoor air pollutants are generated through activities such as cooking, cleaning and smoking, as well as emitted from building materials and indoor surfaces like carpets, plywood, painted walls, floor or furnishing (Carslaw et al. [4]). Furthermore, they can also ingress from outdoors and indoor environments often contain higher concentrations of air pollutants than outdoors (Wolkoff et al. [5]). Moreover, indoor air quality can be further deteriorated through insufficient ventilation of the building (Bornehag et al. [6]).

\subsection{Indoor air pollutants}

One group of commonly occurring pollutants indoors are volatile organic compounds (VOCs), organic compounds with a high vapor pressure and a boiling point between $50^{\circ} \mathrm{C}$ and $260^{\circ} \mathrm{C}$ (Meininghaus et al. [7]). Common indoor VOCs are carbonyls, benzene, toluene, xylenes, styrene and terpenes like limonene and $\alpha$-pinene (Nazaroff and Weschler [8]). Important indoor carbonyl compounds include formaldehyde, acetaldehyde and acrolein, particularly as they demonstrate potentially harmful effects on human health (Morrison and Nazaroff [9]).

As well as primary emissions, secondary pollutants are formed by chemical reactions between primary pollutants, such as aldehydes and ketones (Morrison and Nazaroff [9]). Recent evidence has shown that secondary indoor air pollutants can be more harmful for human health than primary species (Nazaroff and Weschler [8]) and may be responsible for some of the observed health effects indoors (Terry et al. [10]). Such effects include skin and oral irritation, as well as mutagenic and carcinogenic potential (Uhde and Salthammer [11]).

\subsection{Surface production of secondary pollutants}

Different materials commonly used in the indoor environment like building materials, furniture, carpets, paints etc., emit primary pollutants. These primary pollutants can react to form secondary pollutants, either through gas-phase chemistry, or through interactions at surfaces (figure 1).

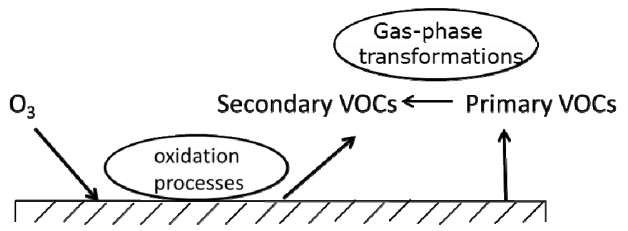

Figure 1: Primary VOC emission from surfaces and secondary VOC production following surface deposition of ozone. 
The primary emissions of VOCs that are emitted from indoor materials and surfaces are typically non-bound, low weight compounds (Wolkoff [12]). These emissions strongly influence indoor air quality during the initial period after installation of new materials and particularly in the first 12 months (Wang and Morrison [13]). However, formation of secondary pollutants can be prolonged relative to primary emissions from the surface (Uhde and Salthammer [11]).

Ozone $\left(\mathrm{O}_{3}\right)$, nitrogen dioxide $\left(\mathrm{NO}_{2}\right)$ and sulphur dioxide $\left(\mathrm{SO}_{2}\right)$ deposit readily on indoor surfaces. Following deposition to the surface, they can interact with the surface to produce secondary species. For instance, surface reactions with ozone can lead to a range of secondary compounds, such as aldehydes and ketones, but also fatty acids and alcohols (Hodgson et al. [14]; Grontoft and Raychaudhuri [15]). For instance, a sample of carpet exposed to ozone was found to emit $8-80 \mu \mathrm{g} / \mathrm{m}^{2} / \mathrm{h}$ of 2-nonenal (Morrison and Nazaroff [9]).

The German Committee for Health Related Evaluation of Building Products (AgBB) identified more than 150 compounds that can be distinguished during emissions from building products (Schripp et al. [16]). Table 1 presents the most common primary and secondary VOCs formed through surface emission/interaction.

Table 1: Primary and secondary VOCs from surface emissions and interactions (Hodgson et al. [14]; Morrison and Nazaroff [9]; Knudsen et al. [17]).

\begin{tabular}{|c|c|c|}
\hline Surface & Primary VOC & Secondary VOC \\
\hline Carpet & $\begin{array}{l}\mathrm{C}_{11}-\mathrm{C}_{13} \text { alkenes } \\
\text { Cycloalkenes } \\
\text { 4-phenylcyclohexane } \\
\text { Dodecanol } \\
\text { Branched alkenes } \\
\text { Aliphatic aldehydes } \\
\text { Benzene }\end{array}$ & $\begin{array}{l}\text { Increased production of } \mathrm{C}_{11}-\mathrm{C}_{13} \\
\text { aliphatic n-aldehydes } \\
\text { Unsaturated aldehydes (mostly } \\
\text { 2-nonanal, hexanal, heptanal, } \\
\text { 2-octanal, decanal) } \\
\text { Ketones: 2-butanone, } \\
\text { 2-pentanone, 2-hexanone, } \\
\text { 2-heptanone }\end{array}$ \\
\hline $\begin{array}{l}\text { Painted gypsum } \\
\text { board }\end{array}$ & $\begin{array}{l}\text { 2-Butoxyethoxyethanol } \\
\text { 1,2-Propandiol } \\
\text { Texanol }\end{array}$ & $\begin{array}{l}\text { Formaldehyde } \\
\text { Acetone } \\
\text { Acetaldehyde } \\
\text { Decanal } \\
\text { Fatty acids }\end{array}$ \\
\hline Plywood & $\begin{array}{l}\alpha \text {-pinene } \\
\text { d-Limonene } \\
\text { Aliphatic aldehydes }\end{array}$ & $\begin{array}{l}\text { Formaldehyde } \\
\text { Acetaldehyde } \\
\text { Benzaldehyde } \\
\text { Pentanal, Hexanal, Heptanal, } \\
\text { Octanal, Nonanal }\end{array}$ \\
\hline $\mathrm{PVC}$ & 2-Butoxyethoxyethanol & $\begin{array}{l}\text { 2-Ethyl-1-hexanol } \\
\text { Phenol }\end{array}$ \\
\hline
\end{tabular}


The deposition rate of a gas to a surface will depend on the surface, as different building products have different sorption properties. For instance the ozone deposition velocity onto carpet is $0.036 \mathrm{~cm} / \mathrm{s}$, whereas on linoleum it is $0.0007 \mathrm{~cm} / \mathrm{s}$ (Grontoft and Raychaudhuri [15]). Some types of surfaces like glass or vinyl flooring are poor ozone sinks while carpets and other soft based materials react with ozone rapidly to form a wide range of aldehydes and ketones (Lamble et al. [18]). Nevertheless, it is probable that new buildings show higher potential for production of secondary pollutants following surface interaction in the indoor environment than old ones (Wang and Morrison [19]). Thus, indoor air pollution is expected to be higher in new buildings. Moreover, different activities in the indoor environment can influence secondary pollutant concentrations. Cooking or cleaning activities increase the potential for pollutant sorption onto surfaces and subsequent production of secondary pollutants (Park and Ikeda [20]).

Recent research shows that the human body might be a sink for ozone and consequently, an additional source of indoor secondary pollutants (Fischer et al. [21]). Human skin contains lipids, fatty acids and squalene, low-volatility compounds that contain double carbon-carbon bounds and make the surface of the body very reactive with ozone (Fischer et al. [21]). Several compounds like acetone, 4-oxopentanal, 6-methyl-5-hepten-2-one and geranyl acetone are recognized as key products from the reaction of human skin oil components with ozone (Fischer et al. [21]).

In this paper, we investigate the deposition rates of ozone onto different surfaces found commonly in the indoor environment. We will investigate the impact on ozone concentrations, as well as explore the possible secondary species that can be formed and their likely concentrations under different ventilation conditions.

\section{Methods}

\subsection{Indoor air quality modelling}

\subsubsection{INDCM model}

In the absence of comprehensive indoor air measurements, the best way to predict indoor air pollutant concentrations is through the use of an indoor air quality model. Modelling studies are necessary to provide insight into indoor air quality, as well as to inform focused measurements. An indoor air detailed chemical model (INDCM) developed by Carslaw [1] and improved by Carslaw et al. [4] is used in this study to investigate indoor air chemistry and particularly that of surface interaction following deposition. The model uses a comprehensive chemical mechanism called the Master Chemical Mechanism, MCM v3.2 (http://mcm.leeds.ac.uk/MCM/), and it considers the chemical breakdown of a wide range of indoor air pollutants. Reactions with $\mathrm{O}_{3}, \mathrm{OH}, \mathrm{NO}_{3}$ and photolysis where relevant initiate the chemical degradation process to form secondary 
compounds. Reactions follow until carbon dioxide and water are finally formed (Terry et al. [10]). The model includes terms that describe deposition onto surfaces, indoor-outdoor exchange and photolysis, both by attenuated outdoor light and artificial lights indoor (Carslaw [1]). The model has been modified to better estimate surface loss and production rates, through the addition of reactions that account for deposition onto individual specified surfaces, rather than assuming a homogenous surface as in previous versions of the model.

For the purpose of this study, we assumed a typical detached house in the UK, with a volume of $312 \mathrm{~m}^{3}$ and total surface area for deposition of $484.8 \mathrm{~m}^{2}$ (Cuellar-Franca and Azapagic [22]). Important surfaces for deposition indoors are: furniture $\left(17.1 \mathrm{~m}^{2}\right)$, hard flooring materials $\left(11.4 \mathrm{~m}^{2}\right)$, carpets together with soft furniture $\left(159.3 \mathrm{~m}^{2}\right)$ and painted walls $\left(229 \mathrm{~m}^{2}\right)$ (Cuellar-Franca and Azapagic [22]). The surface area of a human body was estimated as $2 \mathrm{~m}^{2}$ for adults and $1 \mathrm{~m}^{2}$ for children, and we assumed that two adults and two children were in the house (Fischer et al. [21]). We have then investigated loss rates of indoor air pollutants onto different surfaces and production rates of secondary pollutants following these interactions.

\section{Results and discussion}

The type of surface is key for ozone deposition and secondary pollutant production. We have carried out a number of runs to investigate which type of indoor surface is the most reactive one. We have assumed first, no surface deposition (resulting in an ozone concentration in the house of $22.8 \mathrm{ppb}$ ) and then the addition of one surface at a time to the house through subsequent runs. The resultant ozone concentrations are shown in figure 2.

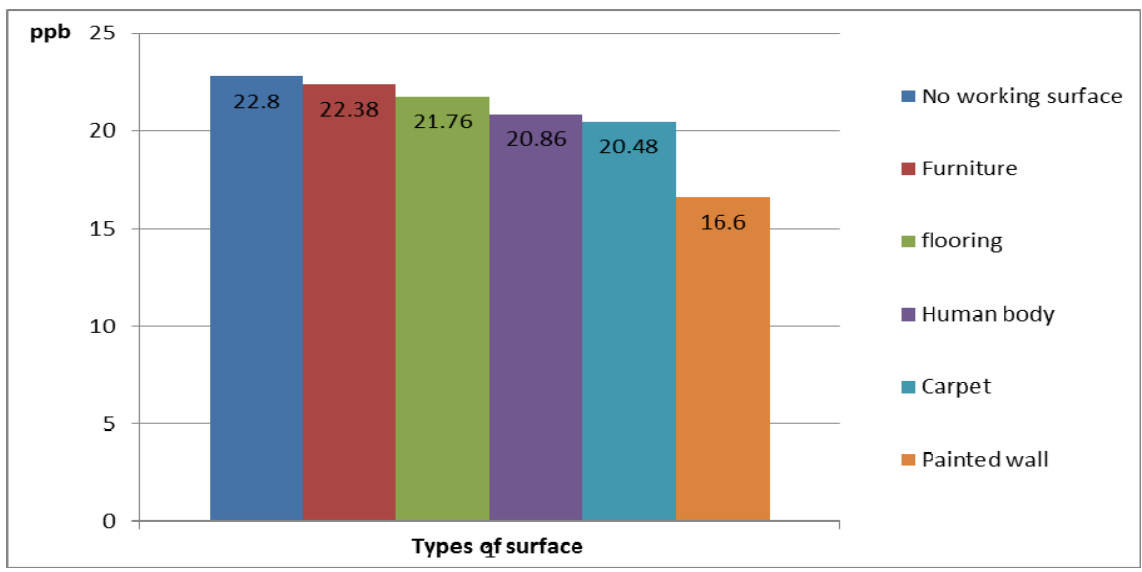

Figure 2: Ozone concentration (in ppb) in the house assuming the subsequent addition of different types of surfaces for each model run relative to a background concentration of $22.8 \mathrm{ppb}$ in the house in the absence of any surface deposition. 
The results have shown that the highest ozone deposition was onto the painted wall ( $\sim \mathrm{ppb})$, despite the deposition velocity being relatively low but in the same time, the surface are of the wall was adequately large. Interestingly, human bodies can compete with the other removal processes and lead to around $1 \mathrm{ppb}$ of ozone removal.

For the next stage of the analysis, we looked at the surface production of aldehyde species following ozone deposition onto carpets. Results from our model show that ozone deposition onto carpets was significant $(2.32 \mathrm{ppb})$. Morrison and Nazaroff [9] found that an exposed sample of carpet was found to emit $8-80 \mu \mathrm{g} / \mathrm{m}^{2} / \mathrm{h}$ of 2-nonanal. Nicolas et al. [23] reported rates for hexanal and heptanal emission of $2.9 \mu \mathrm{g} / \mathrm{m}^{2} / \mathrm{h}$.

By adding these emission rates into our model, we found that concentrations of these aldehyde species increased by between $0.5-1 \mathrm{ppb}$ each compared to runs without the emissions. This analysis will now be expanded to include the secondary products formed through ozone deposition onto other surfaces, as well as investigating similar reactions for $\mathrm{SO}_{2}$ and $\mathrm{NO}_{2}$.

\section{Conclusions}

This study has identified emissions of indoor air pollutants from surfaces. It emphasizes the production of potentially harmful primary and secondary pollutants from different materials used indoors. Further research will define the final composition of secondary VOCs in indoor air, their production rate and their impact on other aspects of indoor air quality.

\section{Acknowledgement}

This $\mathrm{PhD}$ research is sponsored by European Commission regarding Marie Skłodowska-Curie Actions as part of 'CAPACITIE' project.

\section{References}

[1] Carslaw N. A new detailed chemical model for indoor air pollution. Atmos. Environ, 41, pp. 1164-1179, 2007.

[2] Jurvelin J. et al. Personal Exposure Levels and Microenvironmental Concentrations of Formaldehyde and Acetaldehyde in the Helsinki Metropolitan Area, Finland. Journal of the Air and Waste Management Association, 51, pp.17-24, 2011.

[3] Salthammer et al., Formaldehyde in the Indoor Environment. Chemical Reviews, 110(4), 2010.

[4] Carslaw N. et al. A significant Role for Nitrate and Peroxide Groups on Indoor Secondary Organic Aerosol. Environ. Sci. Technol., 46, pp. 92909298, 2012.

[5] Wolkoff P. et al. Human reference values for acute airways effects of five common ozone-initiated terpene reaction products in indoor air. Tox. Letts., 216, pp. 54-64, 2013. 
[6] Bornehag C.G. et al. Dampness in Buildings and Health. Indoor Air, 11, pp. 72-86, 2001.

[7] Meininghaus R. et al. Interaction of volatile organic compounds with indoor materials - a small-scale screening method. Atmospheric Environment, 33, pp. 2395-2401, 1999.

[8] Nazaroff W. and Weschler C. Cleaning products and air fresheners: exposure to primary and secondary air pollutants. Atmospheric Environment, 38, pp. 2841-2865, 2004.

[9] Morrison G., Nazaroff W. Ozone Interactions with Carpet: Secondary Emissions of Aldehydes. Environmental Science and Technology, 36, pp. 2185-2192, 2002.

[10] Terry et al. Occupant exposure to indoor air pollutants in modern European offices: An integrated modelling approach. Atmospheric Environment, 82, pp. 9-16, 2014.

[11] Uhde E., Salthammer T. Impact of reaction products from building materials and furnishing on indoor air quality - A review of recent advances in indoor chemistry. Atmospheric Environment, 41, pp. 31113128, 2007.

[12] Wolkoff P. How to measure and evaluate volatile organic compound emissions from building products. A perspective. The Science of the Total Environment, 227, pp. 197-213, 1999.

[13] Wang H. and Morrison G. ozone-surface reactions in five homes: surface reaction probabilities, aldehyde yields, and trends. Indoor Air, 20, pp. 224-234, 2010.

[14] Hodgson A.T. et al. Sources of formaldehyde, other aldehydes and terpenes in a new manufactured house. Indoor Air, 12, pp. 235-242, 2002.

[15] Grontoft T., Raychaudhuri R. Compilation of tables of surface deposition velocities for $\mathrm{O}_{3}, \mathrm{NO}_{2}$ and $\mathrm{SO}_{2}$ to a range of indoor surfaces. Atmos. Environ, 38, pp. 533-544, 2004.

[16] Schripp T. et al., Application of proton-transfer-reaction-massspectrometry for Indoor Air Quality research. Indoor Air, 24, pp. 178-189, 2014.

[17] Knudsen H.N. et al. Sensory and chemical characterization of VOC emissions from building products: impact of concentration and air velocity. Atmospheric Environment, 33, pp. 1217-1230, 1999.

[18] Lamble S.P. Corsi R.L., Morrison G. Ozone deposition velocities, reaction probabilities and product yields for green building materials. Atmospheric Environment, 45, pp. 6965-6972, 2011.

[19] Wang H., Morrison G., Ozone-Initiated Secondary Emission Rates of Aldehydes from Indoor Surfaces in Four Homes. Environmental Science and Technology, 40, pp. 5263-5268, 2006.

[20] Park J.S., Ikeda K. Variations of formaldehyde and VOC levels during 3 years in new and older homes. Indoor Air, 16, pp. 129-135, 2006.

[21] Fischer A. et al. Ozone removal by occupants in a classroom. Atmos. Environ., 81, pp. 11-17, 2013. 
[22] Cuellar-Franca R.M, Azapagic A. Environmental impacts of the UK residential sector: Life cycle assessment of houses. Building and Environment, 54, pp. 86-99, 2012.

[23] Nicolas et al. Reactions between ozone and building products: Impact on primary and secondary emissions. Atmospheric Environment, 41, 31293138, 2007. 